\title{
BEYOND THE GAZE TRANSLATIONS AS A NORM-CRITICAL PRAXIS IN THEATRE FOR CHILDREN AND YOUTH
}

\section{ANNA LUNDBERG}

This article is based on the project Experimental theatre: Intersectional encounters between dramatic art, school and academia, financed by the Swedish Research Council. It is an action research project on interactive dramatic art based at ung scen/öst (Östgötateatern), an experimental theatre group for children and young people. Malin Axelsson is the group's artistic director. Project manager Anna Lundberg has a background in drama studies and gender studies. The troika of dramatic art-schoolacademia provides an empirical focus, coupled with a closer analysis of the artistic processes between children and adults based on productions by ung scen/öst. What happens with the staging when the method involves open collaboration and shared learning? How is knowledge and meaning negotiated in artistic endeavors? The project includes two performances and a publication. The project received financial support from the Swedish Research Council for the period 2012-2013. This article focuses on translation practices at ung scen/öst, the creative processes within the project built by the group as a form, i.e. director, ensemble (actors), researcher and other members of the artistic team exploring ideas and expressions and creating theatre together.

Keywords: theatrical translation, feminist translation theory, norm critical pedagogy, desire, children's theatre, youth theatre, gender, sensorium, agential realism, materialism

An empty stage, immersed in darkness. The room is quiet, except for the steady sound of a beating heart. Out of the darkness, two male bodies appear, walking towards each other, coming close, halting face to face under a single spotlight. Wearing white tank tops with arms and shoulders naked, the young men seem ghost-like under the pale light. The audience, consisting mainly of teenagers, stares at the two men, who, in turn, stare at each other. One of them raises his arm slowly to put his hand on the other man's naked shoulder. The sound of the heart keeps pounding; the quiet room is shivering with anticipation: What will happen next? Indeed, what does happen when two lightly dressed young men touch onstage in a dark, silent room, and in front of a teenage audience? Wildly unexpected and unpredictable things, as it turns out, when the scene unfolds.

This is the scene that this article will explore, paying close attention to the intersections between physical contact, norm-critical ambition, the onstage translation of meaning and matter, and the capacity of theatrical art to engage with different parts of the sensorium, hence moving beyond the young audience's gaze. ${ }^{1}$ 


\section{ENCOUNTERING UNG SCEN/ÖST: AIM, METHOD, THEORETICAL STANCE}

This article is based on an interactive research project carried out during 2012 and 2013 at ung scen/öst (young scene/east), a playhouse for children and youth, situated in the Eastern part of Sweden. ${ }^{2}$ At the heart of ung scen/öst lies an interest in maintaining an active dialogue with a young audience on social and cultural issues in need of careful treatment. Issues to do with gender, sexuality, structures of power, and knowledge about embodiment, racism, age, new media et cetera. The playhouse is also known for its commitment to exploring new texts, aesthetics, and methods. Thus, ung scen/öst is located within the contemporary Swedish tradition of Brecht-inspired children's theatre that emerged during the 1970s. ${ }^{3}$ The young audience, aged 6-18, visit the theatre mainly during school hours as part of their education. Hence, the discourse of education intersects with the discourse of stage art.

The interactive design of this research project meant that I, a scholar trained in feminist and intersectional studies of culture, spent two years working on the productions in close collaboration with the theatres artistic team. Hence, I was included in the artistic processes from early planning to premiere and beyond. In 2012, ung scen/öst produced a show addressing teenagers called D en magiska cirkeln (The Magical Cirde). The show was designed as a set of loosely connected scenes in which the audience and the actors, together and through magical interventions, investigated and experimented with the meanings of matter and words. It was a kind of joint exploration of the semantic, material and political building blocks of language, taking its point of departure in curiosity: What is time? What is love? What is reality and how do we sense it? Through asking nave questions about the familiar order of everyday life (Whats the point of writing a journal when you hide it away from everyone else? Why does one keep secrets?) naturalized and selfexplanatory aspects of life were revisited and seen through fresh eyes. ${ }^{4}$ The narrative and spatial setting, a gigantic archive with numerous rooms and sections, was inhabited by a group of wizards who collectively worked hard at trying to map and make sense of the so-called real world out there, the world from which the audience came. Hence, the crafty magicians showed great interest in the young subjects who entered the theatre. In order to collect as much information as possible about the so-called real world the magicians kept staring, asking questions, examining the audiences appearance at close range. All this for the purpose of asking accidental visitors to help them figure out the riddles of the exotic and peculiar place called the real world. ${ }^{5}$ The actors/magicians all wore dramatic makeup and wigs of waist-length white hair arranged in various styles. The performance took place in most parts of the playhouse: in the loft and the foyer, on the small and main stages, outdoors, in front of the theatres main entrance as well as indoors. Sometimes, the audience was divided into smaller groups and sometimes the whole crowd (up to 90 people) was gathered together in order to take part in a joint event on the main stage. Some scenes were based on a high degree of interaction between the actors and the audience, while others gathered the audience to observe the magicians performances. In this way, the audience was positioned as outside observers as well as part of the magical, theatrical event. ${ }^{6}$

From this rich, multi-layered show, I have chosen to focus on a single scene, called Love Machine, which explores the intersections between meaning, matter, and touch. Approaching L ove Machine, I have chosen close reading as a method, since it allows careful consideration of different levels of analysis: the nitty-gritty details as well as discursive aspects come under careful scrutiny, which enables us to notice things that otherwise would have gone unnoticed. Rather than trying to establish readings of overarching narratives, close reading opens up ways to inquire into the specifics of a certain situation. Since the method is labor intensive and time consuming, the empirical scope is often limited to a chosen aspect, a fragment or a section of a wider setting. Close reading nevertheless relies on larger interpretative frameworks as well as the readers 
socio-critical standpoint; hence, the reading needs to be properly situated. ${ }^{7}$ Thus, the close reading carried out in this article is situated within feminist theoretical work on translation, matter/materialism and norm-critical pedagogy.

Given the central position of negotiations over words, meaning and materiality in the show, and given ung scen/öst's habit of critically and radically turning the taken for granted upsidedown, I cannot find a more suitable starting point for my analysis than the act of theatrical translation work and the opportunities and struggles it implies. Interactive theatre for children and youth is a cultural and social setting characterized by swarming agents of different ages and social backgrounds, contributing to a myriad of actions, thoughts, traditions, languages, ideologies, bodies, desires, and directions regarding knowledge, art, and ideology. They create meetings, mergers, and clashes, misunderstandings, transformations, and translations of different pace and intensity. This situation implies a constant negotiation over meaning and matter, which in turn implies constant translation work. The act of translation will thus be my tool for mapping a fraction of this endless chain of negotiations, framed by the staging of L ove Machine. I shall now briefly delineate the articles three-fold theoretical toolbox, starting with feminist translation.

\section{TRANSLATION AS AGENCY}

In feminist theory, translation is regarded as both an artistic and a political opportunity to negotiate over meaning. As a result, feminist translation theory aims to highlight, even flaunt, the translator and the act of translation, making it visible and of importance in order to denaturalize linguistic patriarchal hierarchies of power, which rely on stability and unity. Hence, feminist translation theory emphasizes translation as the production of difference, multiplicity and transformation, rather than a normative striving for sameness and equivalence. ${ }^{8}$ The feminist translator is thus an agent who actively negotiates gendered and sexed meanings within and on the borders of patriarchal linguistic discourse. ${ }^{9}$ Thus,
Sherry Simon (and later, Trinh T. Minh-ha) states that it is impossible for beauty (stylistic traits) and fidelity (faithful treatment) to coexist in translation. ${ }^{10}$

\section{THE MEANING OF MATTER}

Feminist translation theory derives its poetics from the French feminist language theory of its foremost theorists, Hélène Cixous and Luce Irigaray, with a focus on écriture féminine, i.e. what Elaine Showalter describes as the inscription of the female body and female difference in language and text. ${ }^{11}$ Consequently, one of the core issues for feminist translation theory is: How can we phrase the body? How can we create new expressions, new poetic languages, leaving the male-dominated symbolic system behind, when writing the body? The meaning of the body, the ways in which the body is interpreted and translated, thus become important in feminist translation. This focus on the body, and the inbetweens and ruptures in acts of translation, taps into recent feminist discussion on materiality and matter, and the interplay of the material and the discursive. Karen Barad calls her endeavor agential realism, elaborating on the ways in which the material nature of practices comes to matter. In Barad's view, both human and non-human agency are accounted for in discursive practice, in the mergers between the material and the discursive. ${ }^{12}$ Barad's theorization of agential realism is thus my second theoretical tool, since, as we shall see, it is important to take her inclusion of non-human agency into account when approaching L ove Machine, a scene in which meaning and matter are negotiated, intersecting with the human sensorium.

\section{NORM-CRITICAL PEDAGOGY}

The third theoretical tool consists of work on norm-critical pedagogy. Critical negotiations over the meaning of normative and naturalized hierarchies of gender and sexuality have become a regular element in Swedish public debate, and in art, but over the last decade they have also entered the realm of Swedish education. Norm-critical approaches to gender, sexuality and desire, where 


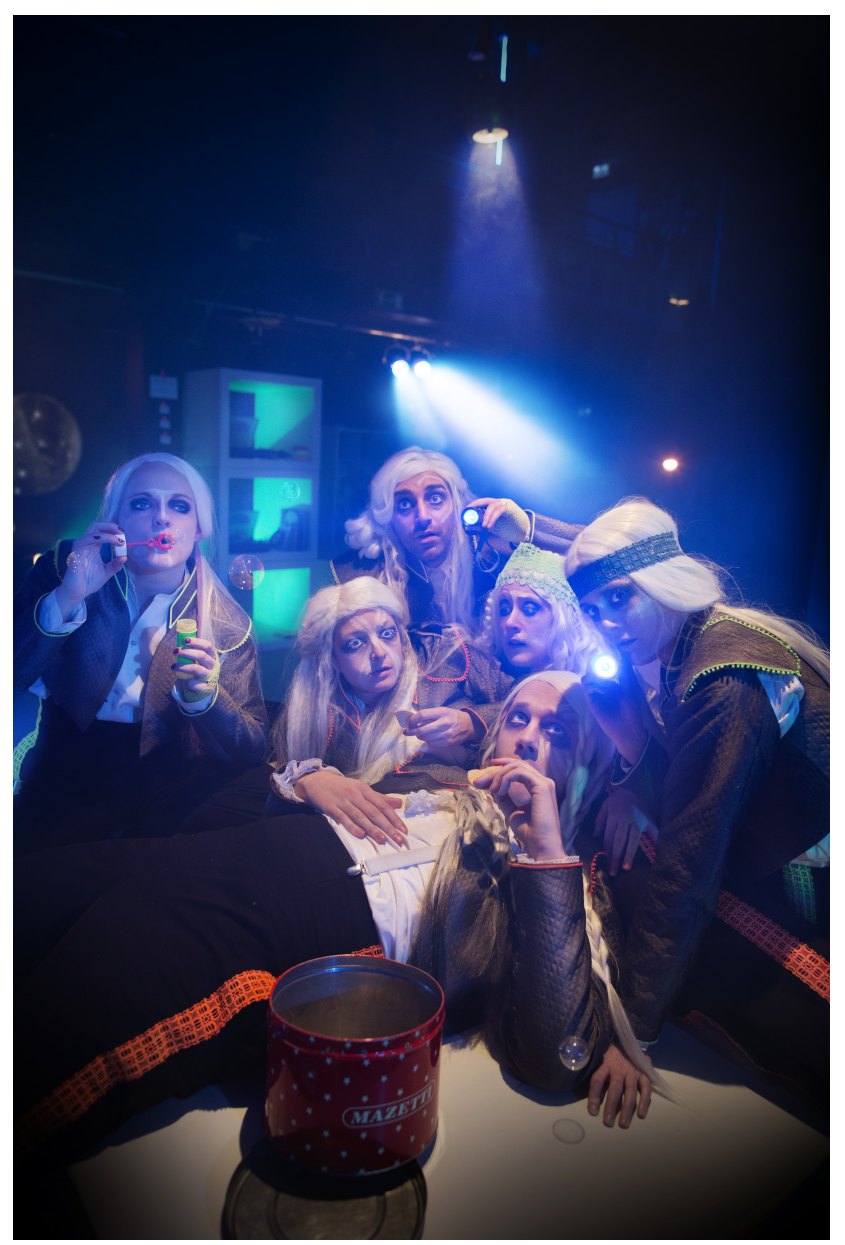

The M agic Cirde, ung sœen/ öst. From left: M aria $\mathrm{G}$ ranhagen, L inda Kunze, A shkan $\mathrm{G}$ hods, Jenny M öller Jensen, Martin Waerme and E llen N orlund. Photo M ark us $\mathrm{G}$ årder.

the charmed circle of valued heteronormality ${ }^{13}$ is challenged, have become somewhat influential in Swedish teaching situations in elementary schools over the past decade, framed by the concept of norm-critical pedagogy. Pupils, as well as teachers, are encouraged to think critically in order to question and change oppressive norms and positions, in order to prevent bullying and discrimination. ${ }^{14}$ Norm-critical pedagogy draws on queer pedagogy and feminist pedagogy; however, it aims for a broader understanding of queer critique, moving beyond an exclusive focus on sexuality, but also avoiding the heteronormative analysis often established in feminist pedagogy. ${ }^{15}$

Critical analysis of gender and sexuality in youth culture has been conducted by a range of scholars and in a range of ways, thereby approaching issues similar to the ones upon which this article focuses: ${ }^{16}$ to name but a few. Under the leadership of artistic director Malin Axelsson, ung scen/öst has developed the habit of mainstreaming norm-critical perspectives into their work on theatre for young audiences. With the theoretical framework in place, it is now time to approach Love Machine and the various agents involved in the production of the scene.

\section{LOVE MACHINE: WHEN MATTER MAKES ITSELF HEARD}

As the name suggests, L ove Machine is a scene addressing the meaning of the production of love: What is love and how does the materiality of love take shape? In building the scene, the work performed by ung scen/östs sound designer Elize Arvefjord and lighting designer Magnus Mikaelsen played key roles. During a meeting with the artistic team, Elize introduced a technical solution through which tactile movements, physical contact between two bodies, were translated into a sound that might be described as that of a dated electronic organ. Two of the actors each held a microphone cable, which had been cut back to the copper wires at one end. When the two actors touched each other, the physical contact generated a sound by closing the circuit. Technically, the transition between touch and body occurred through the potential difference (the voltage across an electrical circuit through the body), and this converted the result into a value played via a keyboard. The higher the value, the higher the note. Depending on how much the actors were perspiring and where they were touching each others bodies (in relation to the location of the cable), the resistance, and hence the potential difference, changed and so did the sound in the form of higher or lower notes. Heavy perspiration (which removes salt from the body) led to greater conductivity and a louder sound. The artistic team became excited over the theatrical possibilities presented by this kind of technology and built the scene around the dramatic effects that it enabled. Hence, Love Machine was outlined as follows: 
The large room is immersed in darkness, apart from a cone of light above a one-meter tall white cube. The young audience is seated on the floor, along the walls around the main stage. Two of the actors, Ashkan Ghods and Martin Waerme, emerge from the darkness at the edge of the scene, moving from opposite directions towards the singular cube and the light. They have taken off their wigs and jackets; underneath, they are shaven-headed and wearing white tank tops. They look ghost-like, still wearing dramatic wizard makeup. Their arms rest down by their sides and, in one hand, they are each holding the cable with bare copper wires (the cables are black and almost invisible in the dark room). They meet at the cube and climb up onto it, standing in front of each other, staring. Apart from a muffled humming, pulsating sound, like a heartbeat, there is silence. It is an intimate scene, the two men standing with their bare arms and shoulders very close to each other. Martin lifts an arm to place his hand on Ashkan's shoulder. The reaction from the audience comes without fail: same-sex touching on stage is met with sounds of disgust in the young audience. Before Martin's hand has landed on Ashkan's shoulder, the soundscape has been invaded by pretend retching, sniggering, and snorting giggles. Nevertheless, Martin's hand lands on Ashkan's shoulder. In that same moment, something happens that changes the audiences reactions: through the two cables, the same-sex touching is translated into sound, and every time the two men lift their hands to touch each other again, a new sound occurs. Every time skin touches skin, a musical noise fills the room, a call like some psychedelic improvisation on an ageing electronic organ. It is a strange sound, oldfashioned, and it causes the obligatory homophobic reactions in the audience to subside. The retching is replaced by shouts of amazement and waves of whispering. Members of the audience lean forward, staring keenly at this touching which is being converted into crazed electronic organ tirades. Ashkan's forehead touches Martin's forehead. A new electronic organ impro. The audience giggles excitedly. Martin's cheek touches Ashkan's back. New sound. The audience chatters in manic whispers. The heartbeat continues to pulse rhythmically through the room. At the same time, the rest of the ensemble approaches the cube and the cone of light: Jenny Möller Jensen, Linda Kunze, Ellen Norlund and Maria Granhagen. Their white tank tops and bald heads glow in the darkness. They glide towards the cube and climb up onto it, touching each other like Martin and Ashkan in the middle. It becomes crowded, and every time a body meets a body, a new sound issues from the electronic organ. Each time a naked arm pulls away to touch again, another sound occurs. The electrical circuit is broken and closed time after time. The different levels of perspiration generate different sounds. The touching, and thus also the sounds, gradually increase in tempo, and finally, all the arms are stretched up towards the light, hands held tightly, resulting in a long and steady crescendo from the electronic organ. Thus resulting in a sound-based climax to a scene that began with a tentative encounter between one mans hand and another mans shoulder.

The audience sits, frozen in silence. The scene dissolves and transforms into the next scene.

\section{THEATRICAL TRANSLATION AND NORM- CRITICAL PEDAGOGY}

As is often the case in theatrical art, a myriad of events occurs simultaneously in L ove Machine. In close reading this line of events, I would like to pay particular attention to three themes drawn from the scene and its negotiation of meaning, starting with the norm-critical effects of highlighted acts of translation as such, continuing with the translations norm-critical renegotiation of the sensorium, and ending with the translation act and its distribution of agency, both human and non-human.

I take my starting point in the onstage scenario where one man's hand is touching another man's naked shoulder, leading to sounds of disgust from parts of the audience. This simple gesture certainly needs to be read against the backdrop of the realm of compulsory heterosexuality ${ }^{17}$ that is highlighted in norm-critical pedagogy. All the subjects present in the room, young and old, are 
well aware of the discursive hierarchical order that ranks certain expressions of heterosexual desire higher than other expressions of desire. Thus, throughout the work on The Magic Cirde, the artistic team critically discussed performances of gender and sexuality onstage. Encounters with young audiences provided knowledge of what they sometimes react strongly to: a female body with hairy armpits, for example, threw parts of an audience off balance and elicited groans of discomfort. When testing L ove Machine in front of an audience, we saw that same-sex encounters aroused similar reactions. Hence, we decided to draw on this, and consistently opened the scene with a same-sex encounter as a norm-critical experiment in interaction with the audience in order to examine the production of meaning and power over gender, bodies, and compulsory patterns of love and desire. In doing so, the magnified acts of translation played a key role. In line with feminist strategies of translation, the scene places the body and its materiality at the center of the production of meaning. However, this is done through elements of surprise when same-sex touch is immediately transformed into the boisterous sounds of an old-school organ. This act of translation is as unexpected as it is pregnant with meaning. The act of translation per se is highlighted here not as a mimetic transfer from one meaning-making discourse to another, but rather as a table-turning event, simultaneously referring back to and highlighting the situation where same-sex touch evoked homophobic reactions, but at the same time pointing forward, adding a new and different interpretation of the situation.

I want to hold on to this specific moment a little longer in order to closely examine what it entails. One of the key ingredients of the scene is surprise. The young audience may be used to the

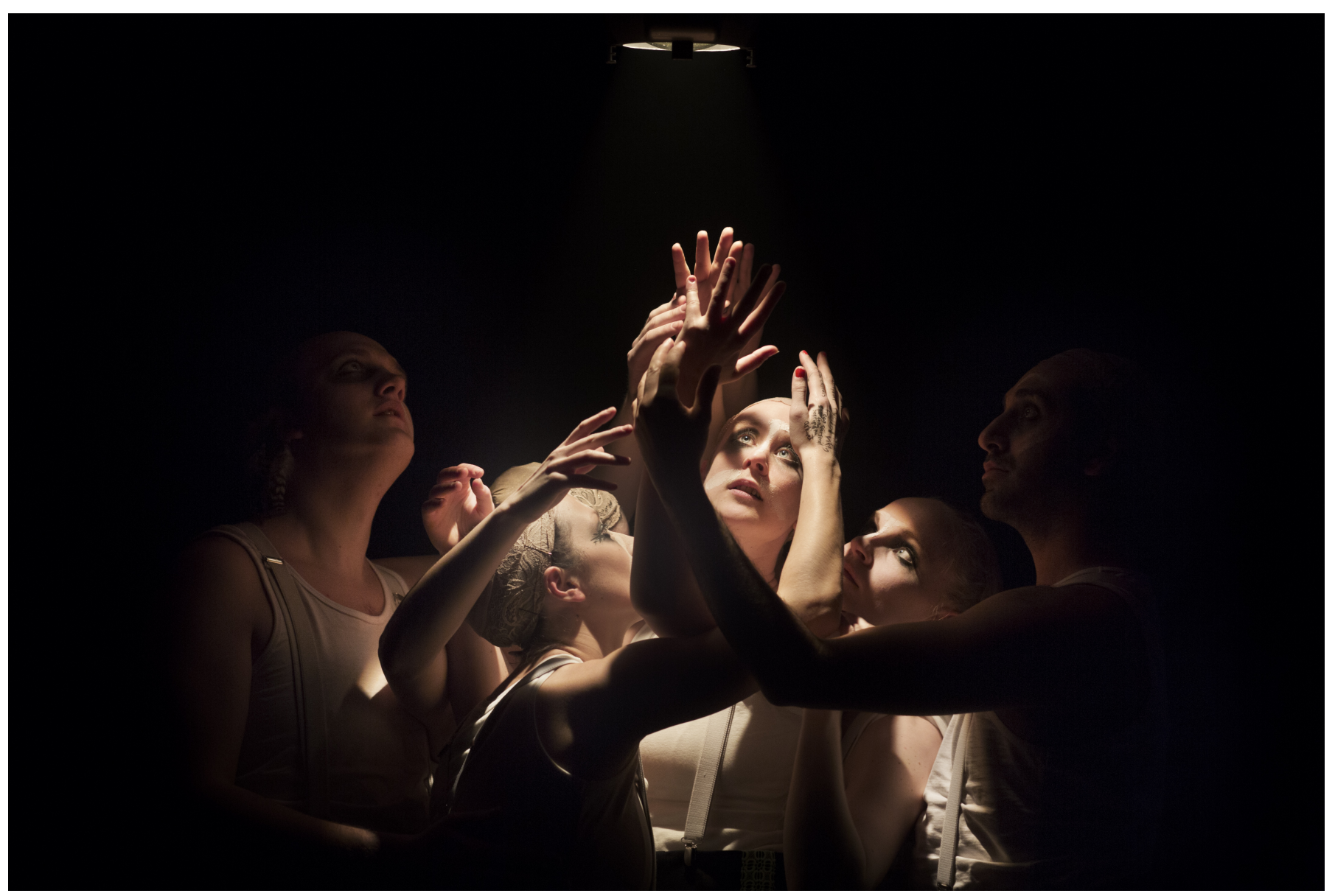

The M agic Cirde, ung sœen/ öst. From left: Martin Waerme, E llen N orlund, L inda Kunze M aria, Jenny M öller Jensen $\mathrm{G}$ ranhagen and $\mathrm{A}$ shk an $\mathrm{G}$ hods. Photo $\mathrm{M}$ ark us $\mathrm{G}$ årder. 
adult world encouraging them to reflect critically upon gender and sexuality. Thus, the same-sex touch may not come as a total surprise. Nevertheless, whatever the audience expected to happen next onstage, loud, psychedelic sounds from an organ, out of nowhere, and without further explanation, was definitely not it. The abrupt shift and the unexpected sound makes the predictable line of events come to a halt. The compulsory homophobic reactions turn into confusion, excitement, and laughter over the queer sound effects. Where do they come from? How can queer touch turn into an equally, or even more, queer sound, and what does the translation do to the queerness of same-sex touch? The interaction is quite powerful, forcing the audience out of habitual behavior, flinging the situation into a new and unknown orbit. The audience seems to be in on it. The teenagers sit up, awake, and eager to catch the novelty implicit in the new direction of events. The act of translation is repeated again and again as an onstage invitation to the audience to come and play. However, it is ambiguous and secretive in its declaration of new meaning, pointing towards the not yet known, the not yet articulated. Nowhere in the scene is a preferred meaning imposed on the audience. The negotiation over meaning lingers, tantalizing, floating back and forth between members of the audience and the onstage events. As a normcritical tool, I read the scene as an effective way of not only throwing established hierarchies of gender, power, and sexuality off balance, but also opening up space for a critique of the norms of linguistic paradigms that embed subjects as once and for all fixed and coherent. ${ }^{18}$ Hence, the openended translation between touch, embodied materiality, and sound bounces through the room as a ping-pong of potentially infinite rebounds, ${ }^{19}$ negotiating the ways in which individuals and groups are categorized and fixed by language, opening up a less fixed understanding of the subject as shaped through love and desire. In doing so, the scene builds on the artistic joy and feminist promise that are to be found in acts of translation.

Turning to the queer way in which translation from one sense to another operates in Love Machine, a question arises: Can touch be heard? When queer touch turns to queer sound, something interesting occurs in the audience: the crowd collectively leans forward, giggling, peering at what is happening, trying to figure it out through sight. Considering the fact that the unexpected turn onstage is based on sounds, this reaction is not rational. Rather, it is a reminder of the priority that is rendered to sight: What you see is what you get, truth becomes evident through visibility. ${ }^{20}$ According to Bettina Papenburg, Western culture tends not only to divide the sensorium into five separate categories, but also to order them hierarchically, placing vision at the top and touch at the bottom. ${ }^{21}$ Hence, the fact that the audience watching Love M achine leans forward in order to examine and find an explanation through sight is not a coincidence, but rather an example of widespread ocularcentrism. However, in Love Machine, vision is clearly sidestepped, giving space to the agential realism of different kinds of materiality, perceived through other parts of the sensorium. Touch is here transmitted to sound through the active workings of chemistry and physics when sweat, electricity, and copper interact. By repeatedly replacing sight with touch as a privileged sense and blurring the clear-cut divisions between the different senses by translating touch into sound, I would argue that L ove Machine, as a norm-critical gesture, queers and challenges sight as a preferred source of truth, and succeeds in moving beyond gaze. The audience can peer and stare as much as they like, it will not give them any more clarity about what is going on between themselves, their reactions, and the actions taking place onstage. I take the amused giggling and excited whispers as a sign of the room shifting: from repetition of a predictable pattern of reactions governed by heteronormative discourse, to difference, uncertainty, rupture, plurality, and mobility from reinforced power hierarchies to a hitherto unknown transformation, the scene enables a different economy of pleasure, desire, and power. This process is enhanced by the ways in which the scene plays around with the sensorium. It 
produces a different economy of love. Hélène Cixous writes: Thinking is trying to think the unthinkable: thinking the thinkable is not worth the effort. ${ }^{22}$ This effort is what I detect in the unexpected act of translation from the sidestepped sight to touch and sound. There are aesthetic, synonymic points of contact between the sight of bald, perspiring bodies and the sound of a blaring old electronic organ. There is something queer and frail in both these aesthetics; they can be paired up but, at the same time, their means of expression are radically different from each other, so unfamiliar that they create surprise when they meet. These simultaneous tracks of sync and lack of sync bring about theatrical magic, but also politics, knowledge, and negotiation over meaning. Norm-critical thoughts become tactile, which become sound, which become anti-sound, which become new sound, which become touch, which shifts the rooms negotiation of meaning about what is what in the world of matter, love, desire.

This leads me to my third theme, which deals with the distribution of agency in Love Machine. An artistic endeavor may be described per se as an act of translating ideas / knowledge / intuition / emotion into materiality. ${ }^{23}$ However, who, in Godard's terms, is the highlighted translator behind the flaunted act of translation in Love Machine? It is significant to note here that no one on stage utters a single word throughout the scene. Instead, the excited whispering and amused chattering from the audience are the only speech acts taking place. I read the medley of young voices as an important agent and part of the scene, not in the form of single subjects, but rather as a common force based on the shivering waves of rising and subsiding sound. The impulse to give voice to the nonsensical happenings onstage charges the event with anticipation, filling the room, demanding attention, negotiating the meaning of this new and peculiar encounter between touch and sound. This is possible since the actors are silent. In addition to the sound waves produced by the audience, I would like, in line with Barad, to underline the agency of the matters of dynamism in the scene. Questioning the naturalized order of difference between human and nonhuman, ${ }^{24} \mathrm{I}$ want to argue that the chemical and physical aspects of L ove Machine contribute extensively to the scene and its magical meaning-making. The fact that a sweaty body, in connection with another sweaty body through copper and electricity, can constitute a circuit of agents procreating musical sounds is quite spectacular. Hence, I would claim that materiality plays an active role in the scenes meaning-making, in a non-representationalist form, and hence not linked to a specific individual. ${ }^{25} \mathrm{I}$ view $\mathrm{L}$ ove Machine as a forceful demonstration of the power of materiality in dramatic art: In a norm-critical way, the transformation of touch to sound lays bare the imbalance and vulnerability inherent in the heteronormative order, and then resolutely turns everything on its head with the help of sound from an old electronic organ, urging the amazed and giggling audience to rise to the occasion, inviting them to articulate thoughts not yet fully established. Hence, the immodest translator that is active in L ove $\mathrm{M}$ achine cannot be identified as a single subject or an identified group of subjects. Rather, the scene and its negotiations of meaning may be captured through, what Karen Barad has called, productive intra-actions, where agents, both human and non-human, without clear boundaries, penetrate and change each other through entangled practices, ${ }^{26}$ thus collectively producing meaning through a mutual flow of actions.

\section{CONCLUSION}

By means of close reading, this article has attempted to lay bare the ways in which the multifacetted expressions of theatrical art may be employed in order to negotiate what is naturalized, opening up the so-called real world anew. By playing with the sensorium, and by acts of translation which highlight meaning as it turns, shifts, and multiplies through transformation, Love Machine takes a firm grip on the normalized order of love and desire. However, it does not replace it with a new set of rules and behaviors; rather, and by the act of surprise, the scene lingers on the precise moment when translation 
takes off, turning the activities within the room in a new, unexpected direction. Without the agency of matter, expressed through electrical power, copper and sweaty bodies, the scene would have been a lot less poetic, and less powerful. The negotiation over meaning is not conveyed through scenic subjects and their speech acts, but rather through intra-activity between the sum of the agents present in the room, both human and nonhuman.Returning to the silence at the end of L ove Machine, the sound of the outdated organ fades away, the audience as well as the actors are dumbfounded, as if waiting for something.
Waiting for what? No one, not a single subject present in the room, possesses the capacity to reveal the answer to that, since the novelty of the situation is the result of a relational process. In order to unravel the mystery represented by L ove Machine, one needs to come to terms with the alluring idea that the meaning of desire and love is always just around the corner, a secret beyond the gaze, as in not yet, as in almost there, as in completely relational, but never monolithic. ${ }^{27}$ As in the queer, elusive sound of an outdated electronic organ. 


\section{NOTES AND REFERENCES}

1. I would like to thank the reviewers for to-the-point and helpful comments on this article. I would also like to thank members of the artistic team at ung scen/öst for reading and commenting on the text.

2. This research project is financed by the Swedish Research Council. The empirical material and the selected scene have previously been discussed in Lundberg, Anna (2015) “Critical Transformations: On Translation Practices at ung scen/öst”, Yearbook of A rtistic R\& D 2015 Swedish Research Council, Stockholm. This article is a theoretical elaboration of that text.

3. Karin Helander, Från sagospel till barnteatertragedi. Pedagogik, förströelse och konst i 1900-talets svensk a barnteater, Carlsson, Stockholm 1998.

4. cf. Viktor Shklovsky, Theory of Prose, Dalkey Archive Press, Elmwood Park, IL, 1990; Anna Lundberg, “'Will We be Tested on This?', Schoolgirls, Neoliberalism and the Comic Grotesque in Swedish Contemporary Youth Theatre," Culture U nbound, 5, 2013.

5. In addition to the ensemble, consisting of the six actors named in the text, the artistic team comprised the director (Malin Axelsson), assistant director (Moa Backman), dramatist (Tova Gerge), set/costume designer (Anna Dolata), lighting designer (Magnus Mikaelsen), sound designer (Elize Arvefjord) and researcher (Anna Lundberg).

6. cf. David Broster, "Being there: an examination of how children respond and interact to an immersive theatre environment", Theatre for Young A udienoes: A C ritical H andbook, Tom Maguire and Karian Schuitema, eds., IoE Press, London 2012, pp. 117-128.

7. Adelina Espinosa Sánchez, \& Jasmina Luki , "Feminist Perspectives on Close Reading", Theories and Methodologies in Postgraduate Feminist Research, Rosemarie Bukeima, Gabriele Griffin,and Nina Lykke, eds., Routledge, London and New York 2011.

8. Barbara Godard, "Theorizing Feminist Discourse/Translation" Translation, Tessera, 6, 1989.

9. Godard, op cit.; E-chou Wu, "Feminist Translation/Feminist Adaptation: Ang Lee's Sense and Sensibility", On the M ove, Linköping University, Linköping 2013.

http://www.ep.liu.se/ecp_home/index.en.aspx?issue= 095.

10. Sherry Simon, Gender in Translation: Cultural Identity and the Politics of Transmission, Routledge, London, 1996; Trinh T. Minh-ha, E lsewhere, W ithin H ere, Routledge, London and New York 2011.

11. Elaine Showalter, "Feminist Criticism in the Wilderness", in The N ew Feminist C riticism: E ssays on W omen, L iterature, and Theory, Elaine Showalter, ed., Virago, London, 1986; Sherry Simon, G ender in Translation: C ultural Identity and the Politics of Transmission, Routledge, London 1996, p. 249.

12. Karen Barad, M eeting the U niverse H alfway: Q uantum Physics and the E ntanglement of Matter and M eaning, Duke University Press, Durham and London 2007.

13. Gayle Rubin, "Thinking Sex: Notes for a Radical Theory of the Politics of Sexuality", Carole Vance, ed., Pleasure and D anger: E x ploring Female Sex uality, Routledge \& Kegan Paul, Boston 1984.

14. Janne Bromseth, "Learning the Straight Script: Constructions of Queer and Heterosexual Bodies in Swedish Schools", Body Claims, Janne Bromset, Lisa Folkmarson Käll, Katarina Mattson, eds., Uppsala University, Uppsala 2009; Leslie Sherlock, "Sociopolitical influences on sexuality education in Sweden and Ireland", Sex E ducation, 4, 2012, pp. 383-396.

15. Janne Bromseth and Renita Sörensdotter, "Normcritical pedagogy", G ender Studies E ducation and Pedagogy, Anna Lundberg and Ann Werner, eds., Swedish Secretariat for G ender Research, 2013.

http://www.genus.se/digitalAssets/1470/1470887_ed u-ped_web.pdf.

16. cf. Ann Werner, "Sexy Shapes: Girls negotiating gender through popular music", G irlhood Studies, 6, nr 2, 2013, pp. 30-46; Hillevi Ganetz, Talangfabriken. Isœnsättningar av genus och sex ualitet i svensk talang-reality, Uppsala: Centrum för genusvetenskap, Uppsala universitet, 2008; and Kalle Berggren, "Degrees of intersectionality: Male rap artists in Sweden negotiating class, race and gender", C ulture U nbound. Journal of Current C ultural Research, 5, 2013. pp. 189-211.

17. Judith Butler, G ender Trouble: Feminism and the Subversion of Identity, Routledge, London and New York 1990.

18. Elizabeth Grosz, T ime Travels. Feminism, N ature, Power, Duke University Press, Durham, London 2005.

19. Simon, op.cit., p. 23.

20. cf. Martin Welton, "Seeing Nothing: Now Hear This...", The Senses in Performanœ, Sally Banes and André Lepecki, eds., Routledge, London and New 
York 2007; Paul Duncum, “An Eye Does Not Make an I", Studies in A rt and E ducation, 53(3), 2012, pp. 182-193.

21. Bettina Papenburg, "Grotesque Sensations:

Carnivalising the Sensorium in the Art of Wangechi Mutu", C arnal aesthetics: Transgressive Imagery and Feminist Politics, Bettina Papenburg \& Marta Zarzycka, eds., Tauris, London 2013.

22. Hélène Cixous, Three Steps on the L adder of W riting, Columbia University Press, New York 1993, p. 38.
23. Lena Martinsson \& Annica Karlsson Rixon, "Trots allt", T idsk rift för genusvetensk ap, 1, 2013, pp. 5-24.

24. Barad, op.cit.

25. Ibid.

26. Ibid.

27. cf. Elizabeth Grosz, "A Thousand Tiny Sexes: Feminism and Rhizomatics", G illes D eleuze and the Theatre of Philosophy, Constantin V. Boundas \& Dorothea Olkowski, eds. Routledge, London and New York 1994.

Anna Lundberg is a researcher and lecturer at the Department of Gender Studies, Linköping University. With a background in the subject of drama and feminist cultural analysis, since 2011 she has conducted action research together with ung scen/öst, Östgötateatern's stage for children and young people. In 2008, she defended her thesis Anything but Serious. The Comic Female Grotesque in Contemporary Swedish Popular Culture. 